\title{
Effects of antenatal nutrition counselling on dietary practices and nutritional status of pregnant women: A quasi-experimental hospital based study
}

\author{
Rameeza Kaleem ${ }^{1}$, Muhammad Adnan ${ }^{2}$, \\ Mahnaz Nasir ${ }^{3}$, Tayyaba Rahat ${ }^{4}$
}

\begin{abstract}
Objective: To assess the effects of nutrition education intervention on dietary practices and nutritional status of pregnant women.

Methods: In this quasi-experimental study, 215 pregnant women were enrolled from Gynae OPD, Sir Ganga Ram Hospital, Lahore, Pakistan during 2017-18. Dietary practices were assessed using the usual intake form and scoring was done against food guide pyramid. Nutritional status was evaluated by anthropometric measurements and biochemical estimation. In addition to nutrition counselling, each woman was prescribed with supplements commonly used during pregnancy. Dietary habits and nutritional status were reassessed after two months. The women lost to follow up were $21(9.8 \%)$ therefore data obtained from 194 women were subjected to final analysis by using SPSS 20.

Results: The age of women ranged between 18 and 38 years. Those who never attended a school were $14.4 \%$; poor $46.0 \%$; and working $3.7 \%$. The comparison between pre- and post-counselling dietary practices showed improvement in the numbers of women taking recommended portions of bread \& cereals $(79.4 \%$ vs. $95.9 \%, p=<0.001)$; vegetables $(50.5 \%$ vs. $64.9 \%, p=0.004)$; milk \& dairy products $(38.1 \%$ vs. $81.4 \%$, $\mathrm{p}=<0.001)$; and a reduction in the numbers of women taking recommended portions of meat \& bean $(100.0 \%$ vs. $94.8 \%, p=0.002)$. The frequency of women taking recommended diet as per food guide pyramid improved from $3.1 \%$ to $37.1 \%$. Vitamin $D$ status also showed improvement in the numbers of women with normal levels of serum vitamin $D(7.1 \%$ vs. $33.3 \%, p=0.079)$.

Conclusions: Overall, nutrition counseling showed positive effects on nutritional status of pregnant women. Thus, the nutrition counseling must be an essential part of antenatal care for all pregnant women in the setting.
\end{abstract}

KEYWORDS: Counselling, Dietary supplements, Pregnancy, Prenatal care, Vitamin D.

How to cite this:

doi: https://doi.org/10.12669/pjms.36.4.1919

Kaleem R, Adnan M, Nasir M, Rahat T. Effects of antenatal nutrition counselling on dietary practices and nutritional status of pregnant women: A quasi-experimental hospital based study. Pak J Med Sci. 2020;36(4):632-636. doi: https://doi.org/10.12669/pjms.36.4.1919

This is an Open Access article distributed under the terms of the Creative Commons Attribution License (http://creativecommons.org/licenses/by/3.0), which permits unrestricted use, distribution, and reproduction in any medium, provided the original work is properly cited.

\section{INTRODUCTION}

Correspondence:

Dr. Rameeza Kaleem, MBBS, MMCH, MD

Head of Department Social \& Preventive Paediatrics

Fatima Jinnah Medical University,

Lahore, Pakistan.

Email: drrameezakaleem@gmail.com

* Received for Publication:

November 4, 2019

* Accepted for Publication:
March 19, 2020
Pregnant women have higher nutritional requirement; whereas poor dietary practices in terms of food frequency and quality may cause nutritional deficiencies. ${ }^{1}$ Several studies have evaluated the association between prenatal dietary practices and pregnancy outcome..$^{2-4}$ In maternal outcomes, it is associated with gestational weight and risk of anemia. In fetal outcomes, it is 
associated with birthweight and risk of preterm birth. Thus, healthy eating habits are essential for the wellbeing of pregnant mothers and better pregnancy outcome. ${ }^{5}$

Vitamin D deficiency (VDD) is a widespread micronutrient deficiency; and it may put pregnant mothers at risk of developing gestational diabetes mellitus, ${ }^{6}$ preeclampsia, ${ }^{7}$ and can increase the risk of preterm labor, poor fetal growth, and adverse neonatal outcome. ${ }^{8}$ National nutrition survey 2011 revealed that $51 \%$ pregnant Pakistani women were anaemic, $46 \%$ vitamin A deficient and $68.9 \%$ suffering from vitamin $\mathrm{D}$ deficiency. ${ }^{9}$

Nutrition counselling is a recommended approach to improve nutritional status of pregnant women. The $\mathrm{WHO}$ recommends that pregnant mothers should be supported to eat healthy and balanced diet for preventing nutritional deficiency. ${ }^{5}$ The reviews of literature show that several studies had evaluated the pregnant women's knowledge, practices, and source of information regarding diet in pregnancy. Very few studies assessed the effects of nutrition counselling on their dietary practices and nutritional status. Therefore, this study was aimed to assess the effects of nutrition counselling on dietary practices and nutritional status of pregnant women seeking antenatal care at a public sector hospital.

\section{METHODS}

The quasi-experimental study was carried out at Sir Ganga Ram Hospital, Lahore, Pakistan from September 2017 to February 2018. Ethical clearance No.09-Medicine/IERB dated 04.07.2017 was obtained from Institutional Ethics Review Board, Fatima Jinnah Medical University/ Sir Ganga Ram Hospital, Lahore, Pakistan. Informed written consents were taken from all volunteer pregnant women. Total 215 pregnant women of gestational age 19-29 weeks, visiting the facility for the first time to seek antenatal care, were enrolled by non-probability purposive sampling technique. Pregnant women reporting any illness or taking supplements before enrollment were excluded.

At baseline, all pregnant women were interviewed for demographic characteristics such as age, gestational age, education, family income, etc.; and subjected to the measurements of body weight, height, hemoglobin level, and vitamin D level etc. Routine antenatal checkup was done by a consultant gynaecologist and prenatal supplements were prescribed. Anthropometric measurements were done by trained lady health visitor. Mid upper arm circumference (MUAC) of the left upper arm at the midpoint between the tip of the shoulder and the tip of the elbow was measured by using MUAC tape. Serum vitamin $D$ levels were estimated by using ELISA method. Normal vitamin D levels ranged between 30-100 $\mathrm{ng} / \mathrm{mL}$, insufficient between $20-30 \mathrm{ng} / \mathrm{mL}$, and deficient $<20 \mathrm{ng} / \mathrm{mL}$. A clinical nutritionist took detailed dietary history using usual intake form. According to their dietary assessment, nutritional counselling was done and diet charts purposefully designed for the study were provided.

All participants were followed up for two months. Then, a second interview was conducted in which post-counselling data were collected. Compliance with advised dietary practices and supplements was assessed. Women who were taking recommended servings from all five groups were labelled as having appropriate dietary practices. Similarly, a second blood specimen was collected to measure the improvement in vitamin D level.

Statistical Package for Social Sciences (SPSS) version 20 was used for data analysis. The women lost to follow up were $21(9.8 \%)$ therefore data obtained from 194 (90.2\%) women were subjected to final statistical analysis. Numerical variables such as age, MUAC and vitamin D levels were described by using mean \pm standard deviation form. Categorical variables such as demographic characteristics and food frequency were discussed in frequency (percentage) form. Pre- and postcounselling dietary practices and vitamin D status were compared by using chi square test. P-value $\leq 0.05$ was considered significant.

\section{RESULTS}

The mean age of 194 pregnant women was $26.4 \pm 4.8$ years (ranged between 18 and 38 years). The women who never attended a school were $14.4 \%$; under-matric $27.5 \%$; and graduate $18.1 \%$. Only $3.7 \%$ women were doing a job. The assessment of family income per month showed that $46.0 \%$ women had earnings of PKR 20,000 or less; and others had between 20,000 and 50,000 PKR. The women experiencing first pregnancy were $3.3 \%$. Overall, mean MUAC was $27.81 \pm 4.63 \mathrm{~cm}$.

The comparison between pre- and postcounselling dietary practices showed improvement in the numbers of women taking recommended 
Table-I: Comparison of pre- and post-counselling dietary practices.

\begin{tabular}{llccc}
\hline FOOD GROUPS & & $\begin{array}{c}\text { Pre-counselling } \\
(n=194)\end{array}$ & $\begin{array}{c}\text { Post-counselling } \\
(n=194)\end{array}$ & p-value \\
\hline $\begin{array}{llcl}\text { Bread, cereals, pasta, rice and potato } \\
\text { group (6-11 servings per day) }\end{array}$ & Recommended or above & $154(79.4 \%)$ & $186(95.9 \%)$ & $<0.001$ \\
& Below recommendation & $40(20.6 \%)$ & $08(4.1 \%)$ & \\
Vegetables group & Recommended or above & $98(50.5 \%)$ & $126(64.9 \%)$ & 0.004 \\
(3-5 servings per day) & Below recommendation & $96(49.5 \%)$ & $68(35.1 \%)$ & \\
Milk and dairy products group & Recommended or above & $74(38.1 \%)$ & $158(81.4 \%)$ & $<0.001$ \\
(Aim to eat 3 servings per day) & Below recommendation & $120(61.9 \%)$ & $36(18.6 \%)$ & \\
Fish, poultry, meat and bean group & Recommended or above & $194(100.0 \%)$ & $184(94.8 \%)$ & 0.002 \\
(Aim to eat 2 servings per day) & Below recommendation & $00(0.0 \%)$ & $10(5.2 \%)$ & \\
Fruits group & Recommended or above & $80(41.2 \%)$ & $130(67.0 \%)$ & $<0.001$ \\
(2- 4 servings per day) & Below recommendation & $114(58.8 \%)$ & $64(33.0 \%)$ & \\
\hline
\end{tabular}

servings of five food groups as shown in Table-I. The frequency of women taking bread \& cereals servings equivalent or above recommendation was further improved from $79.4 \%$ to $95.9 \%(\mathrm{p}=<0.001)$. Likewise, one half of the total women were taking recommended servings of vegetables, and the numbers were significantly increased from $50.5 \%$ to $64.9 \%(p=0.004)$. Though, the frequency of women with appropriate intake of milk \& dairy products was the lowest among the food groups underinvestigation, but a remarkable post-counselling development was revealed $(38.1 \%$ vs. $81.4 \%, \mathrm{p}=$ $<0.001)$. In meat and bean group, an unexpected and significant reduction in the numbers of normal practicing women was observed $(100.0 \%$ vs. $94.8 \%$, $p=0.002)$. A slight increase in the numbers of women having plenty of fluids could be achieved $(74.2 \%$ vs. $78.4 \%, p=0.339)$. Overall, the frequency of women taking recommended diet as per food guide pyramid was improved from $3.1 \%$ to $37.1 \%$.

The assessment of supplement use showed that $19.6 \%$ women did not take any supplement. Among supplement users, $70.1 \%$ women used iron, $55.5 \%$ used calcium, $50.5 \%$ used folic acid, and $44.8 \%$ used vitamin D. When participants were categorized into two age groups, it was revealed that the age group 18-35 years had significantly lower mean levels of vitamin D than of age group 36-49 years (16.5 \pm 8.22 vs. $31.0 \pm 9.54)$; however, post-counselling mean vitamin $\mathrm{D}$ levels significantly improved from $16.5 \pm 8.22$ to $23.82 \pm 15.25$ ( $p=<0.001$ ) within age group 18-35 years. Pre- and post-counselling mean levels of vitamin D were low in both literate and illiterate groups and the difference was not significant. Within group, both literate $(14.4 \pm 2.5$ vs. $27.3 \pm 15.5, \mathrm{p}=0.029)$ and illiterate $(17.3 \pm 19.0$ vs. $23.9 \pm 15.8, \mathrm{p}=0.021)$ revealed significant improvement. Pre- and post-counselling mean levels of vitamin D were also low in both poor and low-middle income groups and the difference was not significant. Within group, both poor $(17.8 \pm 10.0$ vs. $23.9 \pm 15.3, p=0.027)$ and low-middle income group $(16.0 \pm 6.8$ vs. $24.8 \pm 16.6, p=0.004)$ showed significant improvement.

Table-II: Comparison of pre- and post-counselling vitamin D status.

\begin{tabular}{lccc}
\hline Vitamin D status & $\begin{array}{c}\text { Pre-counselling } \\
(n=194)\end{array}$ & $\begin{array}{c}\text { Post-counselling } \\
(n=194)\end{array}$ & $p$-value \\
\hline Deficient $(<20 \mathrm{ng} / \mathrm{ml})$ & $143(73.8 \%)$ & $69(35.7 \%)$ & \\
Insufficient $(20-29 \mathrm{ng} / \mathrm{ml})$ & $37(19.0 \%)$ & $60(31.0 \%)$ & 0.079 \\
Normal $(30-100 \mathrm{ng} / \mathrm{ml})$ & $14(7.1 \%)$ & $65(33.3 \%)$ & \\
Toxicity $(>100 \mathrm{ng} / \mathrm{ml})$ & $00(0.0 \%)$ & $00(0.0 \%)$ & \\
\hline
\end{tabular}


Pre-counselling frequencies of vitamin D deficiency and insufficiency were $73.8 \%$ and $19.0 \%$, respectively. None of the participant had vitamin $\mathrm{D}$ level above normal. Postcounselling frequencies of vitamin D deficiency and insufficiency were $35.7 \%$ and $31.0 \%$, respectively. The comparison between preand post-counselling vitamin D status showed improvement in the numbers of women with normal levels of serum vitamin D $(7.1 \%$ vs. $33.3 \%$, $\mathrm{p}=0.079)$. Table-II.

\section{DISCUSSION}

The World Health Organization (WHO) recommends the use of nutrition education and counselling to improve the nutritional status of pregnant women. ${ }^{5}$ Therefore, the present study evaluated the effects of nutrition counselling on dietary practices and nutritional status of pregnant women. Zelalem et al. assessed pregnancy specific dietary knowledge and practices of pregnant women of Addis Ababa and reported improvement in knowledge $(53.9 \%$ vs. $97.0 \%)$ and practices $(46.8 \%$ vs. $83.7 \%$ ) after nutrition education intervention by healthcare providers. ${ }^{10}$ Similarly, Fallah et al. evaluated awareness level of Iranian pregnant women and observed significant improvement after nutrition education intervention ( $3 \%$ vs. $31 \%, \mathrm{P}=<0.001)$. However, the progress in awareness level was independent of maternal age, education and obesity. ${ }^{11}$ Diddana et al. also provided nutrition education based on Health Belief Model to Ethiopian pregnant women and reported significant improvement in good dietary practice $(56.5 \%$ vs. $84.1 \%, \mathrm{P}=<0.001) .{ }^{12}$ Garg et al. also reported that individual nutrition counselling and regular follow up can improve the nutritional status of pregnant women. ${ }^{13}$ Hence, the key finding of present study was consistent with the results of other studies that nutrition education improves the dietary knowledge, practices, and nutritional status of pregnant women. ${ }^{10-13}$

Bruins et al. reported that nutritional deficiency may persist even with primary nutrition interventions; therefore, secondary prevention can be more useful approach to address nutritional gaps. Furthermore, the authors stated that secondary prevention is potentially cost-effective mean to reduce healthcare cost and to improve the quality of life of individuals, but is often overlooked or underestimated. ${ }^{14}$ The results reported by Bookari et al. showed that Australian pregnant women valued the healthcare providers as the most reliable source of nutrition information; whereas media and social network were less reliable sources. ${ }^{15}$ The studies emphasized on the need of nutrition education by the healthcare workers; and on useful interaction between women and the healthcare providers. ${ }^{10,15}$ Similarly, the nutrition education intervention given by the clinical nutritionist in this study evidenced the usefulness of nutrition counselling and suggests that pregnant women seeking antenatal care should be provided with individual nutrition counselling.

Limitations of this Study: It includes small sample size without control, short duration of study and follow up period, study population mainly from poor class and limited resources to provide prescribed supplements to the participants.

Conclusion: Overall, nutrition counselling showed positive effects on nutritional status of pregnant women. Thus, the nutrition counseling must be an essential part of antenatal care for all pregnant women in the setting.

Acknowledgements: We acknowledge Dr. Farah Zahoor and Ms. Fatima Tariq for their support and assistance in the collection of data; and Mr. Asif Javed for blood specimen collection and sample analysis.

Grant Support \& Financial Disclosures: The study was funded by scaling up nutrition academia and research network Pakistan (SUNAR.Pak).

Conflict of interest: The authors have no conflict of interest.

\section{REFERENCES}

1. Nana A, Zema T. Dietary practices and associated factors during pregnancy in northwestern Ethiopia. BMC Pregnancy Childbirth. 2018;18(1):183. doi: 10.1186/s12884018-1822-1

2. Girard AW, Olude O. Nutrition education and counselling provided during pregnancy: effects on maternal, neonatal and child health outcomes. Paediatr Perinat Epidemiol. 2012;26(S1):191-204. doi: 10.1111/j.13653016.2012.01278.x

3. Ramakrishnan U, Imhoff-Kunsch B, Martorell R. Maternal nutrition interventions to improve maternal, newborn, and child health outcomes. Nestle Nutr Inst Workshop Ser. 2014;78:71-80. doi: 10.1159/000354942

4. Nankumbi J, Ngabirano TD, Nalwadda G. Maternal nutrition education provided by midwives: A qualitative study in an antenatal clinic, Uganda. J Nutr Metab. 2018; Article ID 3987396, 7 pages. doi: 10.1155/2018/3987396 
5. World Health Organization (WHO) [Internet]. e-Library of evidence for nutrition actions (eLENA). Nutrition counselling during pregnancy. [Cited 2019 January 29]. Available from: https://www.who.int/elena/titles/ nutrition_counselling_pregnancy/en/

6. Al-Ajlan A, Al-Musharaf S, Fouad MA, Krishnaswamy S, Wani K, Aljohani NJ, et al. Lower vitamin D levels in Saudi pregnant women are associated with higher risk of developing GDM. BMC Pregnancy Childbirth; 2018;18(1):86. doi: 10.1186/s12884-018-1723-3

7. Bodnar LM, Catov JM, Simhan HN, Holick MF, Powers RW, Roberts JM. Maternal Vitamin D deficiency increases the risk of preeclampsia. J Clin Endocrinol Metab. 2007;92:35173522. doi: $10.1210 /$ jc.2007-0718

8. Dovnik A, Mujezinovic F. The association of vitamin d levels with common pregnancy complications. Nutrients. 2018;10(7):867. doi: 10.3390/nu10070867

9. Bhutta Z, Soofi S, Zaidi S, Habib A, Hussain M. Pakistan National Nutrition Survey, 2011. [Cited 2019 January 29] Available from: https://ecommons.aku.edu/pakistan_fhs_ mc_women_childhealth_paediatr/262

10. Zelalem A, Endeshaw M, Ayenew M, Shiferaw S, Yirgu R. Effect of nutrition education on pregnancy specific nutrition knowledge and healthy dietary practice among pregnant women in Addis Ababa. Clinics Mother Child Health. 2017;14(3):265. doi: 10.4172/2090-7214.1000265

11. Fallah F, Pourabbas A, Delpisheh A, Veisani Y, Shadnoush $M$. Effects of nutrition education on levels of nutritional awareness of pregnant women in Western Iran. Int J Endocrinol Metab. 2013;11(3):175-178. doi: 10.5812/ ijem.9122
12. Diddana TZ, Kelkay GN, Dola AN, Sadore AA. Effect of nutrition education based on health belief model on nutritional knowledge and dietary practice of pregnant women in Dessie Town, Northeast Ethiopia: A cluster randomized control trial. J Nutr Metab. 2018; Article ID 6731815, 10 pages. doi: $10.1155 / 2018 / 6731815$

13. Garg A, Kashyap S. Effect of counselling on nutritional status during pregnancy. Indian J Pediatr. 2006;73(8):687692. doi: $10.1007 /$ bf02898446

14. Bruins $\mathrm{MJ}$, Bird JK, Aebischer $\mathrm{CP}$, Eggersdorfer $\mathrm{M}$. Considerations for secondary prevention of nutritional deficiencies in high-risk groups in high-income countries. Nutrients. 2018;10(1):47. doi: 10.3390/nu10010047

15. Bookari K, Yeatman H, Williamson M. Informing nutrition care in the antenatal period: Pregnant women's experiences and need for support. Biomed Res Int. 2017; Article ID 4856527, 16 pages. doi: $10.1155 / 2017 / 4856527$

\section{Authors' Contribution:}

RK: Concept and design, data collection, critical review, and final approval.

MA: Data collection and interpretation, manuscript writing, and final approval.

MN: Data transformation and interpretation, critical review, and final approval.

TR: Data entry, statistical analysis, critical review and final approval.
Authors:

1. Dr. Rameeza Kaleem, MBBS, MMCH, MD. HOD Social \& Preventive Paediatrics, Department of Social \& Preventive Paediatrics,

2. Mr. Muhammad Adnan, M.Sc. Research Officer, Pakistan Health Research Council (PHRC) Research Center,

3. Dr. Mahnaz Nasir, PhD.

HOD Food Science and Human Nutrition, Department of Food Nutrition, Kinnaird College for Women, Lahore, Pakistan.

4. Ms. Tayyaba Rahat, M. Phil, Statistical Officer,

Pakistan Health Research Council (PHRC) Research Center, 1,2,4: Fatima Jinnah Medical University, Lahore, Pakistan. 